\title{
An Evaluation of Subsidized Rural Primary Care Programs: IV. Impact of the Rural Hospital on Clinic Self-sufficiency
}

\author{
Curtis P. Mclaughlin, DBA, Thomas C. Ricketts, MPH, Deborah A. Freund, PhD, \\ AND CeCIL G. ShePS, MD, MPH
}

\begin{abstract}
Subsidized rural clinics and providers have long depended on the rural hospital for the care of some of their patients; the hospital has also been a source of revenue for these providers and programs. We studied a representative national sample of 116 subsidized rural clinics, focusing on the impact on rural clinic costs and revenues of the use of the hospital by the clinics' providers. Both clinic costs and revenue are reduced by the use of the hospital by rural practice providers, but costs are lowered to a greater extent
\end{abstract}

than revenues, thereby enhancing the financial self-sufficiency of the subsidized clinic. The cost savings affect all aspects of clinic operation, but especially laboratory costs, community services costs, and administrative costs. The dependence of these rural clinics on the hospital indicates that the condition of subsidized rural clinics would be worsened by decreased availability of hospital services. (Am J Public Health 1985; 75:749-753.)

\section{Introduction}

Researchers and administrators have found that the self-sufficiency of rural clinics is enhanced through use of the rural hospital by their physicians. ${ }^{1,2}$ To date, however, most of the information used to support this notion has been anecdotal or based on data from very small samples of clinics. Thus, much of the writing on clinic self-sufficiency leaves the policy maker with the inference that the primary impact of the use of the hospital is to raise clinic revenues, possibly with undesirable cost impacts for patients and third party payors. Valid evidence of the relationship between rural hospitals and rural clinics is important as consideration is given to policies likely to impact the financial survival of both sets of institutions, including the issue of subsidization of clinic and/or hospital operations.

Moscovice and Rosenblatt argue, after studying nine National Health Service Corps and nine Robert Wood Johnson Rural Practice Project clinics, that the rural physician uses the local hospital as a free second office that:

\section{"can be quite profitable because it is free of overhead expense for the rural physician and can often provide the extra income necessary for sustaining the practice."1}

They further indicate that the absence of a hospital limited the growth and productivity of the clinics and providers.

In their study of nine rural practices (eight private and one subsidized), Wallack and Kretz found that the hospital is an important contributor of practice income. They noted that more successful practices derived a much higher proportion of their revenue from the care of hospitalized patients. They also cited the other contributions of the hospital as:

- enhancing the physician's diagnostic capabilities and ability to provide continuity of care;

- contributing to the physician's sense of well-being and maintaining his/her interest in medicine;

- strengthening the patient's confidence and ties to the physician by avoiding referral to other physicians; and

From the Health Services Research Center, the School of Public Health, and the School of Business Administration, at UNC (Chapel Hill). Address reprint requests to Thomas C. Ricketts, MPH, Health Services Research Center, Chase Hall 132-A, University of North Carolina, Chapel Hill, NC 27514. This paper, submitted to the Journal October 23, 1984, was revised and accepted for publication March 4, 1985.

(c) 1985 American Journal of Public Health 0090-0036/85\$1.50
- providing a source of new clientele through emergencyroom contact. ${ }^{2}$

Yet the Wallack and Kretz study said little about subsidized rural practices. The one subsidized practice in their sample was an anomaly to their analysis, being oriented toward ambulatory care, using a sliding fee scale and not always billing for hospital care.

In our study of federally subsidized rural practices ${ }^{3-5}$ there was little doubt that the use of the hospital is closely associated with higher levels of self-sufficiency. The assumption of previous research, however, has been that this is due largely to the revenue that the hospital practice generates. In this paper we address both sides of the self-sufficiency question, revenues and costs.

\section{Methods}

Data

The data are drawn from the National Evaluation of Rural Primary Health Care Programs, a stratified random sample of rural clinics in the United States that have received some form of financial subsidy from governmental, foundation or institutional sources. Programs were stratified by organizational form, region, and single/multiple site structure. A detailed description of this sample and the sampling process has appeared previously. ${ }^{3-5}$ Participants in the overall study included 193 clinics. However, because complete and/or compatible financial data for 1980 , the year covered by this analysis, could not be obtained for all clinics, the present analysis is confined to 116 clinics which were able to provide data for all relevant analysis variables. Scatter plots of the cost, revenue, and size variables indicate that the six largest clinics (total costs over $\$ 3$ million) were outliers which substantially biased our empirical results; hence, they were excluded from the study sample. The distribution of the 116 programs used for this analysis is shown in Table 1. It approximates the original sampling distribution with regard to the three major organizational forms studies: community health centers (CHC), organized group practices (OGP), and primary care centers (PCC).

Data describing the financial operations of the study clinics were drawn either from the Bureau Common Reporting Requirements (BCRR) form for each program receiving some form of federal funding, or directly from the operating records of the clinic if not federally supported. These data were merged for each program with data from other surveys conducted for the National Evaluation Project. 
TABLE 1-Organizational Form, Region, and Site Configuration of Analysis Programs $(N=116)$ and Total Sample Programs $(N=193)$

\begin{tabular}{|c|c|c|c|c|c|c|c|c|c|c|}
\hline \multirow[b]{3}{*}{ Organizational Form } & \multicolumn{6}{|c|}{ Region } & \multicolumn{4}{|c|}{ Site Configuration } \\
\hline & \multicolumn{2}{|c|}{ North } & \multicolumn{2}{|c|}{ Southeast } & \multicolumn{2}{|c|}{ West } & \multicolumn{2}{|c|}{ Single } & \multicolumn{2}{|c|}{ Multiple } \\
\hline & $\mathbf{N}$ & $\%$ & $\mathbf{N}$ & $\%$ & $\mathbf{N}$ & $\%$ & $\mathbf{N}$ & $\%$ & $\mathbf{N}$ & $\%$ \\
\hline 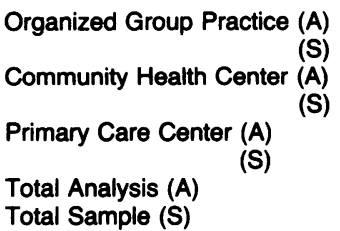 & $\begin{array}{r}17 \\
21 \\
5 \\
7 \\
23 \\
28 \\
45 \\
56\end{array}$ & $\begin{array}{r}14.6 \\
10.9 \\
4.3 \\
3.6 \\
19.8 \\
14.5\end{array}$ & $\begin{array}{r}11 \\
15 \\
9 \\
12 \\
19 \\
28 \\
39 \\
55\end{array}$ & $\begin{array}{r}9.5 \\
7.8 \\
7.8 \\
6.2 \\
16.4 \\
14.5\end{array}$ & $\begin{array}{r}7 \\
9 \\
9 \\
10 \\
16 \\
21 \\
32 \\
40\end{array}$ & $\begin{array}{r}6.0 \\
4.6 \\
7.8 \\
5.2 \\
13.8 \\
10.9\end{array}$ & $\begin{array}{l}15 \\
22 \\
13 \\
15 \\
38 \\
56 \\
66 \\
93\end{array}$ & $\begin{array}{r}12.9 \\
11.4 \\
11.2 \\
7.8 \\
32.7 \\
29.0\end{array}$ & $\begin{array}{l}20 \\
23 \\
10 \\
14 \\
20 \\
21 \\
50 \\
58\end{array}$ & $\begin{array}{r}17.2 \\
11.9 \\
8.6 \\
7.3 \\
17.2 \\
10.9\end{array}$ \\
\hline
\end{tabular}

(A) = Program in Analysis.

(S) = Programs in Total Evaluation Sample.

\section{Dependent Variables}

The major dependent variables chosen for the analysis were: total revenue from clients, third party payers, and local sources; and total operating costs for the clinics. These are the two main components of self-sufficiency which is defined as total revenue/total cost. This definition is based upon earlier work by Feldman, et al, ${ }^{6}$ and Wallack and Kretz. ${ }^{2}$ Revenues include only earned patient care income from direct pay patients or third party payers. Costs include all operating costs, donated services, salaries, depreciation, and debt service.

\section{Independent Variables}

Economic theory suggests that costs are a function of firm output (usually measured for clinics in level of encounters), input prices of employees hired and capital equipment utilized, and control variables measuring unique characteristics of the firm. It is posited that revenue is a function of similar variables. Since previous studies did not present any consensus, an appropriate guide was not available as to what particular metrics would best be applied to these concepts. Therefore, several variables for each of the areas included in the data base were tested for significant correlation with the dependent variables. Variables significant at the 0.10 level were entered into a stepwise regression to develop the most parsimonious subset. ${ }^{8}$ The model was then estimated with ordinary least squares techniques using the significant predictive variables and controls chosen to account for service mix and staffing pattern. Appendix A reports the means and standard deviations of the resulting set of variables.

The regressions contain variables which can be categorized in the following groups: measures of output including services provided, size, proxy measures for staffing and wage structure, and unique characteristics of the practice, including competition, reimbursement, user characteristics, and most importantly the degree to which the hospital was used by providers for patient care, the central concern of this study.

\section{Hospital Use}

The extent of hospital use by clinic patients and providers is represented by the percentage of clinic revenues generated from hospital-based activities. This allows us to measure the relationship between hospital use and self-sufficiency. This percentage is based on directly reported estimates provided by the clinic administrators. We com- pared this estimated figure to another variable representing the proportion of medical and dental encounters in hospital drawn from the BCRR reports. The two were highly correlated, but per cent of hospital revenue was available from more clinics and used in the analysis.

\section{Measures of Output}

Service Variables-The three service variables utilized represent additional services provided by clinics to enhance access and comprehensiveness. We hypothesized that outreach will have a positive impact on revenue and costs, since it will increase demand but be costly to provide. Provision of more services (comprehensiveness) is hypothesized to lead to greater costs and more revenues. Provision of after-hours coverage is hypothesized to have a positive influence on costs, while its impact on revenues is uncertain.

Size-The number of medical and dental encounters generated by the program during 1980 is used to represent the program's size. Encounters are defined as face-to-face patient encounters with a clinic-based physician, nurse-practitioner, physician assistant, dentist, or dental auxiliary. We would expect costs and revenues to increase directly with size. Economic theory posits that there is a non-linear relationship between output (size), revenues, and costs which is best estimated by a cubic function. In order to test for this relationship, the squared and cubed terms of medical encounters were entered in the regressions.

Staffing and Wage Structure-Two measures of staffing patterns and wages paid are used. The average annual wages paid to clinical medical personnel and to administrative personnel were calculated by dividing these personnel costs (including donated National Health Service Corps salaries) by the number of full-time equivalent personnel (including NHSC personnel) in each of the two categories. We hypothesized that costs would be positively related to the annual wages and use of medical personnel. These variables should be positively related to revenues if the use of higher paid and more skilled personnel leads to the ability to provide greater and more profitable services.

Competition-Competition from other community providers may also be important for self-sufficiency considering the hypothesis that the greater the competition, the smaller the clinic's market share is likely to be. Competition is represented by the proportion of primary care providers (physicians, nurse practitioners, physician assistants) in the clinic's service area working in the subsidized program (we called this measure dominance). We hypothesized that the 
TABLE 2-Costs and Revenues Associated with Hospital Use and Control Variables

\begin{tabular}{|c|c|c|}
\hline Independent Variables & $\begin{array}{l}\text { Total Cost } \\
\text { Regression } \\
\text { Coefficients }\end{array}$ & $\begin{array}{l}\text { Total Revenue } \\
\text { Regression } \\
\text { Coefficients }\end{array}$ \\
\hline & \multicolumn{2}{|c|}{ (95\% Confidence Intervals) } \\
\hline \multicolumn{3}{|l|}{ Hospital Use } \\
\hline Hospital Revenues & $\begin{array}{c}-5423.20 \\
( \pm 3531.75)\end{array}$ & $\begin{array}{r}-520.40 \\
( \pm 1583.28)\end{array}$ \\
\hline \multicolumn{3}{|l|}{ Services } \\
\hline Outreach & $\begin{array}{r}+60248.00 \\
( \pm 112713.48)\end{array}$ & $\begin{array}{r}+8347.06 \\
( \pm 505929.6)\end{array}$ \\
\hline Other Primary Care & $\begin{array}{c}+18261.34 \\
( \pm 18069.48)\end{array}$ & $\begin{array}{r}-1107.84 \\
( \pm 18368.46)\end{array}$ \\
\hline After-hours coverage & $\begin{array}{c}-11390.41 \\
( \pm 40974.12)\end{array}$ & $\begin{array}{r}+4170.02 \\
( \pm 18368.46)\end{array}$ \\
\hline \multicolumn{3}{|l|}{ Size } \\
\hline Encounters & $\begin{array}{l}+31.96 \\
( \pm 3.97)\end{array}$ & $\begin{array}{l}+11.76 \\
( \pm 1.78)\end{array}$ \\
\hline \multicolumn{3}{|l|}{ Staffing and Wage Structure } \\
\hline $\begin{array}{l}\text { Medical Wage } \\
\text { Administrative Wage }\end{array}$ & $\begin{array}{l}+7.829 \\
( \pm 6.69) \\
+5.186 \\
( \pm 9.20)\end{array}$ & $\begin{array}{l}+1.773 \\
( \pm 2.98) \\
-0.4344 \\
( \pm 4.12)\end{array}$ \\
\hline \multicolumn{3}{|l|}{ Competition } \\
\hline Dominance & $\begin{array}{c}-12811.33 \\
( \pm 130817.51)\end{array}$ & $\begin{array}{c}+25835.27 \\
( \pm 58645.20)\end{array}$ \\
\hline \multicolumn{3}{|l|}{ Reimbursement } \\
\hline Eligibility & $\begin{array}{c}-23783.57 \\
( \pm 41230.32)\end{array}$ & $\begin{array}{c}+15645.50 \\
( \pm 18483.45)\end{array}$ \\
\hline \multicolumn{3}{|l|}{ User Characteristics } \\
\hline Non-White Users & $\begin{array}{c}+5423.20 \\
( \pm 2202.90)\end{array}$ & $\begin{array}{l}-1559.91 \\
( \pm 937.68)\end{array}$ \\
\hline Latino Users & $\begin{array}{c}+2231.51 \\
( \pm 1767.17)\end{array}$ & $\begin{array}{l}-1252.63 \\
( \pm 792.22)\end{array}$ \\
\hline $\begin{array}{l}\text { R-squared } \\
\text { Adjusted R-squared } \\
\mathbf{N}= \\
\text { F-value }\end{array}$ & $\begin{array}{c}0.8274 \\
0.8091 \\
116 \\
45.317\end{array}$ & $\begin{array}{c}0.7238 \\
0.6946 \\
116 \\
24.777\end{array}$ \\
\hline
\end{tabular}

clinics with high dominance would have higher costs and higher revenues, all other things being equal.

Medicaid Reimbursement-The level of Medicaid reimbursement in the state in which the clinic is located is represented by the quartile index of eligibility for each state ranging from one (indicating that less than 25 per cent of the state's poor are eligible for coverage by Medicaid) to four (representing 75 per cent or more eligible). The percentages are based on federal poverty guidelines and Medicaid rules in effect in 1979. We would expect this variable to have a significant positive relationship to revenues.

User Characteristics-The percentages of clinic users who were non-White or Latino are used to characterize the special attributes of the patients seen in the clinic. These minorities generally present themselves with more complex problems than Whites, ${ }^{*}$ and live in states with less generous Medicaid benefits. We would expect these variables to have a negative impact on revenues and a positive impact on costs.

\section{Results}

The results of a multiple linear regression of costs and revenue on the explanatory variables is shown in Table 2.

Services-Most of the service provision variables had impacts as expected. The presence of outreach services was

* Deprez RD, Pennell BE, Spindler MA: The Impact of Rural Health Clinics on Inpatient Hospital Use and Expenditure. Paper presented at 1984 National Conference on Rural Primary Care, March 18-21, 1984. Albuquerque, NM. found to increase costs and revenues, but the relationship is not strong in either case. The addition of dental, mental health, and social services sharply increases costs but not revenues. The provision of after-hours coverage reduces costs and increases revenues, but not greatly.

Size-As expected, clinic size is strongly related to both costs and revenues. Total costs rose by approximately $\$ 32$ per each additional encounter and revenues by approximately $\$ 12$. These findings imply that larger clinics have more difficulty reaching self-sufficiency, all other things being equal. The differences appear to be due to the high level of subsidization of the clinics in the sample. The squared and cubed terms indicated a linearly increasing relationship between size and the cost and revenue variables over the range we examined. Table 2 , therefore, reports only the linear model.

Staffing and Wage Structure-Higher wages lead to higher costs, as expected.

Competition-Contrary to our expectations, clinic provider dominance is of little importance. A monopoly position leads to somewhat increased revenue as one might expect, but not to increased costs.

Medicaid Reimbursement-If the clinic is located in a state that uses liberal Medicaid eligibility criteria, revenues are increased. However, contrary to expectations, Medicaid "liberality" does not affect costs appreciably.

User Characteristics-As hypothesized, the greater the percentage of minority patients served, the higher the costs and the lower the revenues. As the proportion of non-Whites (Latinos) increases by 1 per cent, the total costs rise $\$ 2,653$ $(\$ 2,231)$ and the revenues drop $\$ 1,553(\$ 1,253)$. This result indicates that high proportions of minority patients tend to jeopardize the financial self-sufficiency of the rural clinic.

Hospital Use-Hospital use has a negative impact on costs and there is a corresponding, but lesser lowering in revenues as well. A sensitivity analysis of the effect of the loss of the hospital inpatient encounters and revenue on clinic costs and revenues using the model in Table 2 indicates that the loss of the hospital practice could result in a reduction of about 0.03 in the self-sufficiency ratio, a 7.5 per cent drop. For each 1 per cent increase in the percentage of hospitalbased revenues, all other things being equal, there is a $\$ 5,423$ decrease in annual clinic costs and a $\$ 520$ decrease in annual clinic revenues. There are several potential reasons for this:

- Sicker, and hence more costly, patients are referred to the hospital. Thus, hospital costs substitute for clinic costs, not only relieving the clinic of costs, but also of any related revenues.

- In some states, clinics are reimbursed by Medicaid, Medicare, and other programs for the average cost per case, rather than by the clinical procedure performed. Clinics in these states cannot increase revenues by charging separately for ancillary services, as is common in many hospitals and other clinics. By shifting higher technology costs to the hospital, they may save on costs without severe effects on revenue.

The size of the coefficients for the per cent of the clinic revenue from hospital patient care in the models reported in Table 2 is consistent with the theory that clinics do triage sicker patients to avoid costs. In an effort to find out more about these costs effects, we analyzed specific cost components in the categories defined in the BCRR system. We modeled regression equations to identify the impact of hospital revenues on each BCRR cost component using each as a dependent variable. 
The analysis of these cost components provides greater support for the "cost substitution" rather than the "revenue enhancement" impact of the rural hospital on subsidized rural clinics. Even though all cost categories were reduced with increased hospital use, the important reductions were in laboratory costs, community services costs (outreach, marketing, patient discharge, transportation, follow-up), and administration.

We examined further the medical and the administrative and facility salary costs and their relationship to hospital use. The reductions in the medical costs accompanying higher levels of hospital revenue were not through salary expense reductions (including those donated by National Health Service Corps personnel), but in purchased services, consultations, supplies, and other costs. Yet, facility maintenance and administrative salaries were markedly reduced, indicating that the hospital does provide free support services that might include administrative functions.

We were not able to identify the impact of the hospital on capital costs. Most clinics did not keep adequate records of capital expenditures and we found that the BCRR system of reporting tended to over-reward reported investment for capital purchases. ${ }^{* *}$ Our sample excluded the few clinics that were institutional extensions of hospitals, so that possible cross-subsidy problems were eliminated. The specifics of these cost regressions are available from the authors.

Unfortunately the corresponding specific revenue effects could not be identified from the available data, since revenues were reported only on an aggregate basis. This was especially frustrating when it came to analyzing the effect of the loss of laboratory and other ancillary revenues on the one hand, and the offset of increased provider fees for in-hospital services on the other. The revenue data were defined in such a way as to make it impossible to separate the income from inpatient services from the income from clinic visits.

\section{Discussion}

We do not know the total impact on the health care system of the substitution of rural hospital for rural clinic care, since we do not know what the hospital charges or collects for the substituted services. Nevertheless, our data indicate that a close relationship between rural primary care clinics and hospitals clearly favors the self-sufficiency of the clinic, mostly through the overall reduction of costs, especially laboratory, community service, and administrative service costs.

The nature of the complementary effect-that of clinic use on hospital admissions, costs and revenues-is even less well understood. Analysis of data on users and non-users of a stratified random sample of 36 closely studied clinics in the National Evaluation Project showed that regular clinic users

\footnotetext{
** One interesting observation from working with BCRR records is that the multi-page formula used to compute any paybacks due the federal government reduces mathematically to the identity that any payback is equal to any excess of revenues over expenses minus capital purchases. Thus, the knowledgeable clinic manager makes a profit when feasible, but sinks the excess into capital purchases.
}

were less likely to be hospitalized and reported fewer hospital days of care. ${ }^{* * *}$ A study of a group of rural health centers in Maine in 1980 revealed similar results (see earlier footnote *). Further, the Maine study found little, if any, effect upon the hospital's admission rates, costs, and revenues after the opening of the clinic chain.

Given the evidence that hospital usage by the rural clinic's providers reduces the costs more than it decreases revenues for these clinics, it would seem easy to make the next step of recommending that these clinics be located close to or in relationship with a hospital. This recommendation repeats those made by others, ${ }^{1,2}$ but gives inadequate attention to the fact that many rural hospitals have their own problems of fiscal stability and survival.

An analysis of rural clinic activities during the 1980-82 recession has shown that a great majority of them can survive in the face of restricted subsidies and a hostile policy environment. ${ }^{10}$ Rural hospitals, on the other hand, have not had the luxury of direct subsidies to help them cover the operating costs of building a client base. Undoubtedly they have been aided by rural clinics which brought new practitioners in their doors. However, a secular trend toward fewer admissions and shorter patient stays, coupled with fiscal pressures brought on by higher operating costs and a federal prospective payment system that reimburses rural hospitals at a much lower rate than urban hospitals, have made the small rural hospitals' future bleak.

While the subsidized rural clinics have survived, they have not prospered nor been able to consistently reach a self-supporting level. They still report self-sufficiency ratios, on average, in the .50 to .70 range. ${ }^{10}$ The loss of the marginal cost savings and revenue from a hospital closing, together with its impact on provider retention and recruitment, have significant implications for the financial stability of small, rural primary care clinics as well.

In our large national sample, the availability of a rural hospital was a major advantage to a struggling rural primary care clinic. Because the providers in most subsidized clinics are paid a salary, the presence of a nearby hospital can increase revenues to the clinic by providing a chance for its practitioners to treat inpatients. In addition, the hospital serves as a laboratory and $\mathrm{x}$-ray resource for a clinic, thus relieving it of capital expenses for costly equipment, ancillary salaries, and overhead that may not be easily recouped due to lower utilization in a rural clinic.

It appears important in making policy decisions to recognize that the costs borne by the rural hospital in part represents the services it provides to local physicians and clinics, costs that would have to be covered some other way, should the hospital be closed as a cost-containment measure or because of low utilization. In considering policies to improve or maintain access for rural populations, the problem of health care services centered on both clinics and their related hospitals needs to be addressed. The two are separate, but related, entities in terms of cost and survival.

*** Wagner EH, Sheps CG, et al: National Evaluation of Subsidized Rural Primary Care Programs: Major Findings and Policy Considerations. Unpublished manuscript, 1984. 


\begin{tabular}{|c|c|c|c|}
\hline Variables & Description & Mean & $\begin{array}{l}\text { Standard } \\
\text { Deviation }\end{array}$ \\
\hline \multicolumn{4}{|l|}{ Dependent } \\
\hline $\begin{array}{l}\text { Total Costs } \\
\text { Total Revenues }\end{array}$ & & $\begin{array}{l}\$ 564,774 \\
\$ 225,970\end{array}$ & $\begin{array}{l}\$ 517,395 \\
\$ 183,368\end{array}$ \\
\hline \multicolumn{4}{|l|}{$\begin{array}{l}\text { Independent } \\
\text { Hospital Use }\end{array}$} \\
\hline $\begin{array}{l}\text { Hospital } \\
\text { Revenue }\end{array}$ & $\begin{array}{l}\text { Percentage of revenues from } \\
\text { inpatient care, } 1980\end{array}$ & 8.87 & 13.04 \\
\hline Services Outreach & $\begin{array}{l}0,1 \text { dummy } \\
1=\text { outreach provided }\end{array}$ & 0.34 & 0.48 \\
\hline Comprehensiveness & $\begin{array}{l}0 \text { to } 9 \text { integer index of } \\
\text { nonclinical primary care } \\
\text { services** }\end{array}$ & 4.67 & 2.53 \\
\hline After-hours coverage & $\begin{array}{l}0,1,2,3 \text { index of extent of } \\
\text { after-hours care }\end{array}$ & 2.20 & 1.11 \\
\hline \multicolumn{4}{|c|}{ 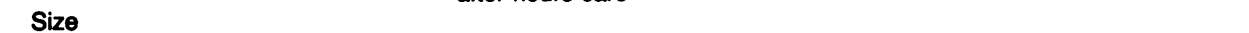 } \\
\hline $\begin{array}{l}\text { Encounters } \\
\text { Staffing and Wage }\end{array}$ & Medical + dental & 17,985 & 13,147 \\
\hline \multicolumn{4}{|l|}{$\begin{array}{l}\text { Staffing and Wage } \\
\text { Structure }\end{array}$} \\
\hline Medical Wage & $\begin{array}{l}\text { Annual wage, medical } \\
\text { employees } 1980\end{array}$ & $\$ 21,413$ & $\$ 6,817$ \\
\hline Administrative Wage & $\begin{array}{l}\text { Annual wage, administrative } \\
\text { employees } 1980\end{array}$ & $\$ 9,938$ & $\$ 4,674$ \\
\hline $\begin{array}{l}\text { Competition } \\
\text { Dominance }\end{array}$ & $\begin{array}{l}\text { Proportion of providers in } \\
\text { community employed in } \\
\text { program }\end{array}$ & 0.44 & 0.33 \\
\hline \multirow{2}{*}{$\begin{array}{l}\text { Reimbursement } \\
\text { Eligibility } \\
\text { User Characteristics } \\
\text { Non-White } \\
\text { Latino }\end{array}$} & $\begin{array}{l}1,2,3,4 \text { quartiles of coverage } \\
\text { of Medicaid in state }\end{array}$ & 2.55 & 1.15 \\
\hline & $\begin{array}{l}\text { Percentage users non-White } \\
\text { Percentage users Latino } \\
\text { origin }\end{array}$ & $\begin{array}{l}12.47 \\
13.54\end{array}$ & $\begin{array}{l}21.74 \\
26.43\end{array}$ \\
\hline
\end{tabular}

$N=116$ for all variables.

Provided at clinic by at least one-half of one full-time employee.

${ }^{*} \mathrm{O}=$ no dental, mental health, or social senvices; 9 = all three are offered; intermediate scores indicate some offering of these services through linkages to other agencies or through visiting providers.

\section{ACKNOWLEDGMENTS}

This study was supported by the Robert Wood Johnson Foundation, the US Department of Health and Human Services, and the Health Services Research Center of the University of North Carolina at Chapel Hill.

\section{REFERENCES}

1. Moscovice IS, Rosenblatt RA: Rural Health Care. New York: John Wiley \& Sons, 1982.

2. Wallack S, Kretz S: Rural Medicine: Obstacles and Solutions for Selfsufficiency. Lexington, MA: Lexington Books, 1981.

3. Sheps CG, Bachar M: Rural areas and personal health services: current strategies. In: Jain SC (ed): Role of State and Local Governments in Relation to Personal Health Services. Am J Public Health 1981; 71(Suppl):71-82.
4. Sheps CG, et al: An evaluation of subsidized rural primary care programs: I. a typology of practice organizations. Am J Public Health 1983; 73:38-48.

5. Ricketts TC, Wagner EW, Konrad TR: An evaluation of subsidized rural primary care programs. II. the environmental contexts. Am J Public Health 1983; 73:406-413.

6. Feldman R, Dietz D, Brooks EF: The financial viability of rural primary care centers. Am J Public Health 1978; 68:981-988.

7. Feldstein PJ: Health Care Economics. New York: John Wiley \& Sons, 1983.

8. SAS Institute: SAS User's Guide: Statistics, 1982 Ed. Cary, NC: SAS Institute, 1982.

9. Aday LA, Anderson R: Access to Medical Care. Ann Arbor, MI: Health Administration Press, 1975; 74.

10. Ricketts TC, Guild PA, Sheps CG, Wagner EH: An evaluation of subsidized rural primary care programs: III. stress and survival, 1981-82. Am J Public Health 1984; 74:816-819. 